\title{
REGIONAL TRAINING INSTITUTE FOR ARAB COUNTRIES
}

The second session of the Regional Training Institute for senior staff of Red Crescent Societies in Arab countries was held in Amman from 7 to 27 July 1973. The seminar, which was organized by the League of Red Cross Societies in active co-operation with the Jordan National Red Crescent Society and its President Dr. Abu-Goura, was attended by twenty-nine persons-including seven ladiesfrom the following countries: Bahrain, Jordan, Kuwait, Saudi Arabia, Sudan, Syria, the Yemen Arab Republic and the People's Democratic Republic of Yemen. The League was represented by Mr. Y. Kiamouche and Dr. Zielinsky, and the ICRC by Mr. M.-A. Boisard.

The seminar participants attended courses conducted by various lecturers. The first few days were given to an analysis of the organization and structure of the International Red Cross. Then the League representatives carried out a practical exercise of relief distribution to the supposed victims of a natural disaster. They publicized National Society activities designed to promote operations, recruit volunteers, extend medical assistance and set up "blood banks". The ICRC representative submitted statements on international humanitarian law and the procedure governing the application of the four Geneva Conventions of $1949{ }^{1}$.

During the second week, Royal University professors lectured on such subjects as the planning, administration and financing of National Societies; the psychological, social or cultural factors affecting the growth of voluntary organizations, and the part which Societies could play in national development and the protection of the environment. During the third week, the participants briefly

\footnotetext{
${ }^{1}$ Plate.
} 


\section{IN THE RED CROSS WORLD}

outlined their Societies' activities with special reference to the recruiting of volunteers, social welfare, co-operation with the ICRC regarding the application of the Geneva Conventions, medical assistance, relief for the victims of natural disasters or armed conflicts, and so forth.

True to the Training Institute's rule that the substance of the talks be furnished by the participants themselves, the experts and professors present confined themselves to leading or animating the discussions, which were of unfailing interest. Coming as they did from countries where human problems arose in different contexts, the participants had an opportunity to compare their experiences. They reached the conclusion that Arab countries offered a vast field of activity for Red Crescent Societies which, as voluntary institutions in permanent contact with the reality of everyday life, could not only contribute to the prevention or lessening of individual suffering, but could play a determinant role in the medicosocial and cultural spheres.

\section{INTERNATIONAL RED CROSS ASSISTANCE IN INDO-CHINA}

The Indo-China Operational Group (IOG) teams are continuing to give support to the National Red Cross Societies' work of relief distribution and medical assistance.

\section{Republic of Vietnam}

The IOG co-operates in the Vietnam Red Cross distributions. In July, more than fifteen thousand families (some 100,000 persons) in 34 provinces were reached by these operations. The nine members of the IOG delegation working in the four regions of the country include four delegates, a doctor and a delegate of the Central Tracing Agency. 